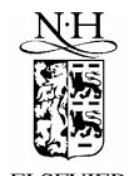

\title{
Private costs and public benefits: unraveling the effects of altruism and noisy behavior
}

\author{
Jacob K. Goeree ${ }^{\mathrm{a}}$, Charles A. Holt ${ }^{\mathrm{a}}$, Susan K. Laury ${ }^{\mathrm{b}, *}$ \\ a Department of Economics, University of Virginia, Charlottesville, VA 22903, USA \\ ${ }^{\mathrm{b}}$ Department of Economics, Andrew Young School of Policy Studies, Georgia State University, \\ Atlanta, GA 30303-3083, USA
}

Received 26 April 2000; received in revised form 10 September 2000; accepted 3 November 2000

\begin{abstract}
An increase in the common marginal value of a public good has two effects: it increases the benefit of a contribution to others, and it reduces the net cost of making a contribution. These two effects can be decomposed by letting a contribution have an 'internal' return for oneself that differs from the 'external' return to someone else. We use this framework in a series of one-shot public goods games in which subjects make choices in ten treatments with no feedback. Contributions are generally increasing in the external return and group size, which suggests that altruism in this context is not simply of the 'warm glow' variety, i.e. giving only for the sake of giving. Contributions are also increasing in the internal return, indicating that decisions are sensitive to the costs of helping others. We specify a logit equilibrium model in which individuals are motivated by own and others' earnings, and in which choice is stochastic. Maximum likelihood estimates of (representative-agent) altruism and logit parameters are significant and of reasonable magnitudes, and the resulting two-parameter model tracks the pattern of contributions across the ten treatments. A richer model reveals some differences in individual altruism coefficients, with more dispersion among male subjects. (C) 2002 Elsevier Science B.V. All rights reserved.
\end{abstract}

Keywords: Alruism; Public good; Contribution model; Experiment

*Corresponding author. Tel.: + 1-404-651-2618; fax: + 1-404-651-0425.

E-mail address: slaury@gsu.edu (S.K. Laury). 


\section{Introduction}

As Ledyard (1995) concludes, there is still no consensus on what is driving the diverse behavioral patterns in public goods experiments. Some plausible factors include altruistic preferences for others' earnings, reciprocal responses to others' contributions, and some degree of confusion and error. The wealth of laboratory data has stimulated a number of theoretical papers that consider preference-based, error-based, and learning-based explanations. ${ }^{1}$ Most subsequent laboratory experiments have used clever designs to eliminate or control for particular factors in order to isolate the effects of others.

Because many issues remain unresolved, it is useful to consider an alternative approach that is more closely tied to economic theory and standard econometrics. In particular, several economists have specified more general models of behavior motivated by altruism and/or relative earnings. ${ }^{2}$ The experiments reported here use both experimental design/control and theory-based econometric techniques to investigate contribution behavior in a series of one-shot public goods games. We are able to obtain precise distinctions by independently varying the net cost of making a contribution and the external benefit to others in the group. We then specify and estimate an equilibrium model that incorporates preferences that depend on others' earnings and noisy decision making.

Before describing our design, it is useful to review the structure of a standard linear public goods game, in which subjects begin with an endowment of 'tokens' that can either be kept or contributed. Each token kept yields a constant monetary return for the subject, and each token that is contributed also yields a constant return, both for that person and for all others in the group. The sum of all group members' returns from the contribution typically exceeds the individual's return from keeping the token, so group earnings are maximized by full contribution. The net monetary loss from making a contribution is the difference between the value of a token that is kept and what the subject earns from a token contributed to the public good. A positive net loss ensures that the Nash equilibrium is to contribute nothing, at least in a one-shot game with no altruistic feelings about others' payoffs.

In the absence of altruism, an individual may make some contributions if the net loss from contributing is relatively small and there is some 'noise' in the decision-making process. Whether these contributions are interpreted as rational responses to unobserved preference shocks or as mistakes, the effects of noise should be greater when the net cost of a contribution is small.

When there is altruism, the net loss from making a contribution should be compared with the benefit that is enjoyed by others in the group. The presence of

\footnotetext{
${ }^{1}$ See Holt and Laury (2000) for a recent survey of theoretical explanations of behavior in public goods games.

${ }^{2}$ See, for example, Andreoni and Miller (2000); Palfrey and Prisbrey (1997); Bolton and Ockenfels (2000); and Fehr and Schmidt (1999).
} 
at least some altruism is suggested by the most consistent treatment effect in linear public goods games: an increase in the common marginal value of the public good will raise contributions. This treatment change confounds two separate factors, however. It increases the marginal value of the public good, thereby lowering the net cost of contributing and raising the benefit to others at the same time. ${ }^{3}$

Following Carter et al. (1992) we allow a costly contribution to have two distinct effects, an 'internal return' to oneself and a possibly different 'external return' to others in the group. In one treatment, for example, a token that is worth 5 cents if kept, returns 4 cents to that person if contributed, but provides an external return of only 2 cents for each other person in the group. Thus the net cost to oneself is 1 cent, and the act of contributing increases each other person's earnings by 2 cents. A modification of the internal return changes the net cost of contributing, without altering the benefits to others. Conversely, a change in the external return alters others' benefits without affecting the cost of contribution.

Carter et al. (1992) conclude that behavior is affected by both internal and external returns. ${ }^{4}$ Although these results are intuitive, we believe that their conclusions can be strengthened with an analysis based on formal economic models and the estimation of the parameters of those models. We let subjects make a series of ten decisions in one-shot games with independent variations of internal and external returns and group size. This 'one-shot' design is a departure from the majority of public goods experiments, in which participants make repeated decisions in a single treatment, with earnings feedback provided between rounds. Although some public goods interactions in the economy may be better modeled as non-repeated, our main motivation for the one-shot design was to mitigate the possibility of reciprocity or strategic attempts to trigger others' reciprocity. In addition, subjects in repeated public goods experiments sometimes become frustrated after they observe that others free ride. 5 Our design allows us to avoid

\footnotetext{
${ }^{3}$ This treatment effect does not preclude reciprocity (either in response to what others have contributed in the past or in anticipation of contributions in the current round). However, it is not clear how an increase in the marginal value of the public good would affect reciprocal contributions, unless one believes that others are more likely to contribute when the value of the contribution is higher.

${ }^{4}$ Carter et al. (1992) report only one (20-person) session per treatment. With random matching in groups of size four, there is some question about whether the individual contributions can be treated as independent observations, given the common exposure to others' decisions that is inevitable in this setup. In this situation, it difficult to infer significance from standard statistical tests, at least without modeling the effects of 'history' on individual decisions.

${ }^{5}$ For example, Chewning et al. (2000) report that one subject considered leaving the experiment early because others were not contributing enough to the public good. Similarly, Laury et al. (1995) present responses to a post-experiment questionnaire in which a number of subjects expressed frustration over the low contributions of others in their group. Unedited written comments included, 'I wish that this weren't done in private because the people in my group screwed me out of a lot of money and I would like to know who they are. Greedy people suck.' 'No one cooperated with my decisions. They made dumb decisions.' 'I tried to make the most \$ not only for myself, but also for my group as well, but everyone in the group was basically out for themselves and placed practically no $\$$ in the group account (including myself); and we all came up short. Don't they understand how it works!!! How frustrating!!!'
} 
the issue of whether and how attitudes towards others' earnings change with good or bad experiences. Another benefit of this design is that it yields independent individual decisions that allow us to evaluate individual differences in altruism. We estimate individual-specific altruism parameters and obtain similar results from a related model in which altruism parameters are drawn from population distributions. We also estimate a non-linear altruism specification.

The experimental design is described in the next section and the data are summarized in the third section. In Section 4, we present a model of altruism with noisy decision making, and report maximum likelihood estimates of altruism and error parameters. The final section concludes. The instructions and individual choice data are contained in the appendices.

\section{Experimental design and procedures}

The experiment was designed to provide a reasonable number of independent individual decisions under a range of payoff conditions. The treatments were selected to facilitate the isolation of separate factors that may cause behavior to diverge from the dominant strategy Nash prediction of zero contributions in all treatments. Subjects were asked to allocate 25 'tokens' between public and private consumption in each of ten treatments, with the relevant treatment chosen ex post by the throw of a ten-sided die. Thus the ten decisions were made with no feedback about others' decisions, and the context is best viewed as a one-shot game.

In each treatment, a token kept earned a constant return of five cents, and a token contributed to the public good earned a return both to the individual contributing and to each other person in the group. Table 1 shows the internal and external returns for each of the ten treatments (the data shown in the lower part of Table 1 will be discussed in Section 3 below). Group size was either two or four. Internal return, which measures how much a person gets back from contributing a token, was either two or four cents. The external return represents how much each other person gets from a token contributed, and ranged from 2 to 12 cents. The

\footnotetext{
${ }^{6}$ This procedure of paying for only one decision after several have been made has been used by others in public goods and bargaining games, e.g. Andreoni and Miller (2000) and Brandts and Schram (1995). An alternative procedure would be to pay for all decisions, which has the advantage of providing higher incentives, although at a higher expense to the experimenter. Whether this has a behavioral effect is an open question. For example, it may be that paying for only one decision induces subjects to think more clearly about the payoff consequences of each decision rather than focusing on relative earnings aggregated over all ten choices.

${ }^{7}$ Carter et al. (1992) used a two-by-two design with high and low internal and external returns and a constant group size of four. Their treatments are roughly comparable to our treatments 1, 4, 6 and 9. Our six additional treatments allow us to examine the effect of larger increases in external return and the effect of changing group size. Moreover, we have 32 independent observations in each of our treatments.
} 
Table 1

Summary of treatments

\begin{tabular}{lcccccccccc}
\hline & \multicolumn{2}{l}{ Treatment } \\
\cline { 2 - 10 } & 1 & 2 & 3 & 4 & 5 & 6 & 7 & 8 & 9 & 10 \\
\hline Group size & 4 & 2 & 4 & 4 & 2 & 4 & 2 & 2 & 4 & 2 \\
Internal return & 4 & 4 & 4 & 2 & 4 & 4 & 2 & 4 & 2 & 4 \\
External return & 2 & 4 & 6 & 2 & 6 & 4 & 6 & 2 & 6 & 12 \\
Mean contribution & 10.7 & 12.4 & 14.3 & 4.9 & 11.7 & 10.6 & 7.7 & 6.7 & 10.5 & 14.5 \\
Median contribution & 10 & 14 & 17 & 5 & 14 & 11 & 7 & 5 & 10 & 16.5 \\
\hline
\end{tabular}

order in which the decisions were listed on the decision sheets follows Table 1, and was such that at least two treatment variables changed between adjacent decisions. All ten decisions were distributed in the same handout, so the order of treatments in Table 1 is not necessarily the order in which the subjects made their choices. In fact, the majority of subjects changed one or more of their decisions before submitting them; overall, $18 \%$ of the choices were changed (57 of 320 total choices). ${ }^{8}$

Notice that the value of a token kept ( 5 cents) is greater than the individual's internal return from a token contributed in all treatments. Thus, the single-round dominant strategy for a selfish participant is to contribute no tokens. However, it is also the case that the total return to participants from a token contributed is greater than the value of a token kept. Thus, full contribution by all would maximize group earnings. Even though the setup decomposes internal and external returns, the basic social dilemma structure of the standard public goods game is preserved.

The participants were recruited from undergraduate classes at the Universities of South Carolina and Virginia, and none had participated in a previous public goods experiment. The 32 subjects each made ten decisions with no feedback, so there are 32 individual sets of ten decisions. Groups of eight subjects were in the same room, but were visually isolated from other participants by the use of 'blinders.' The instructions in Appendix A were distributed and read aloud by the experiment monitor. After participants made contribution decisions for all ten scenarios, the record sheets were collected and the relevant treatment was selected by the throw of a ten-sided die. Matchings (in groups of size two or four) were done with draws of marked ping-pong balls, and the contribution decisions were used to calculate earnings, which were recorded and subsequently returned to participants. Subjects were told in advance that the experiment would be followed by a different decision making experiment, which helped augment their earnings. They were told that their earnings from this experiment would be computed during the second, but

\footnotetext{
${ }^{8}$ We determined this by looking at the decision sheets for cases in which decisions were clearly erased or crossed out.

${ }^{9}$ For example, the change from treatment 4 to treatment 6 corresponds to an increase in the marginal per capita return (MPCR) from 0.4 to 0.8 in a standard public goods game.
} 
were not given any information about the nature of the second experiment. Participants were paid their earnings from the treatment selected, along with a $\$ 6$ participation payment and earnings for the subsequent experiment. Earnings ranged from about $\$ 14$ to $\$ 26$ in sessions that lasted no more than 90 minutes, including subject payment.

\section{Data patterns}

In this section, we examine the primary treatment effects using non-parametric tests. Econometric estimates of a structural model are presented in the next section. The final two rows of Table 1 present summary statistics for the data in terms of number of tokens contributed out of 25 . It is immediately apparent that the highest contributions are for treatments 3 and 10 with high external returns, and the lowest contributions are for treatment 4 with low internal and external returns. Fig. 1 shows average contributions ordered by treatment. Treatments with an internal return of 2 cents are shown on the left of this graph, while treatments with an internal return of 4 cents are shown on the right. For each internal return, bars from left to right reflect contributions in treatments ordered from low to high external return. The bars in the front row correspond to treatments with a group size of two, and bars in the back row are treatments with a group size of four.

The cost of making a contribution has the strongest effect on contribution decisions. When the internal return increases from 2 to 4 cents (reflecting a decrease in the net cost of contributing from 3 cents to 1 cent), contributions increase, both for groups of size of two and four. To see this in the figure, compare the three bars on the left side with the corresponding three bars on the right side

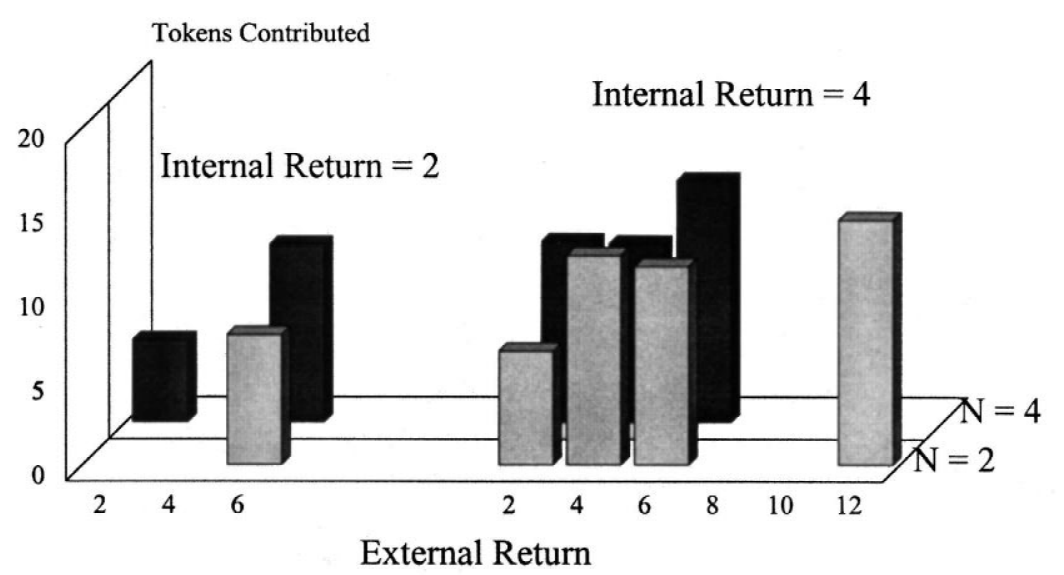

Fig. 1. Average contributions by treatment (number of tokens contributed). 
(skip the bars with external returns of 4 on the right). This treatment effect is significant in nonparametric tests at the $1 \%$ level. $^{10}$

An increase in external return is also associated with an increase in contributions to the public good, as suggested by the tendency for bar heights to increase from left to right in each part of Fig. $1 .^{11}$ With a group size of two and an internal return of 4 cents, a Friedman test rejects the null hypothesis that contributions in the four treatments are the same (Siegel, 1956). Conducting pairwise comparisons, contributions increase significantly when the external return increases from 2 to 4 cents, and also from 6 to 12 cents. However, there is no significant difference in contributions when the external return increases from 4 to 6 cents. Similar results hold for groups of size 4 . With an internal return of 4 cents, a Friedman test again rejects the null hypothesis of no treatment effect. In pairwise comparisons, contributions do not change significantly when the external return increases from 2 to 4 cents, but they do increase when the external return increases from 4 to 6 cents. ${ }^{12}$ For groups of size 4 and an internal return of 2 cents, contributions increase significantly when the external return increases from 2 to 6 cents.

Finally, contributions generally increase with group size, as reflected by the taller bars in the back row of Fig. 1. Contributions decrease slightly when the internal and external returns are 4 cents; otherwise, the effect of group size is positive and significant. ${ }^{13}$ This suggests that contributions are higher when more people will benefit from the contribution (holding constant the per-person benefit of the public good). This conclusion is further supported by data from additional treatments with groups of size 12 , discussed in the next section.

The above results provide some evidence of altruism in subjects' contribution decisions. This altruism is not simply of the warm-glow variety (defined as increased utility from the act of giving, rather than from what the others receive) because it is responsive to the external return and group size. But neither are subjects acting as pure altruists, i.e. they do not behave in a way that maximizes others' earnings. Other-regarding behavior is less common in our data when the private cost of a contribution increases (holding constant the benefit of a

\footnotetext{
${ }^{10}$ Because all participants made decisions in each of the ten treatment conditions, matched-pair test statistics may be computed to establish treatment differences. We use a non-parametric Wilcoxon signed-rank test. There are a number of cases in which subjects make identical decisions in both treatments. Following Siegel (1956), these tied observations are discarded. For the tests reported, there were 20-28 matched pairs (out of a total of 32 possible pairs). Unless otherwise indicated, one-tailed significance tests with significance levels of $1 \%$ are used.

${ }^{11}$ These results are consistent with those of Carter et al. (1992): both internal and external returns have a positive effect on contributions, and the largest effect is from a change in the internal return.

${ }^{12}$ Contributions actually decrease slightly when the external return increases from 2 to 4 cents. This happens also for groups of size 2 when the external return increases from 4 to 6 cents. Notice that the median contribution does not decrease with an increase in the external return for any group size.

${ }^{13}$ Since there is no reason to believe that contributions will be higher with larger group sizes, a two-tailed test was used for these comparisons.
} 
contribution to others). This suggests that behavioral noise, which is sensitive to economic costs, may provide an additional explanation for the observed contributions. The following section presents a formal model of contribution behavior that incorporates both altruism and decision error.

\section{A parametric theory of altruism and noisy decision making}

In a one-shot public goods game, for which it is a dominant strategy for selfish players not to contribute, any contribution is a type of error. This may be due to subject mistakes or an error in the way in which preferences are modeled. In either case, these errors cause data to be dispersed away from the full free-riding outcome, and the degree of dispersion indicates the importance of errors. Following McKelvey and Palfrey (1995), we use a probabilistic choice function to model noisy decision-making, supplemented with a Nash-like equilibrium condition on the consistency of actions and beliefs. A convenient specification for empirical work is the logit probabilistic choice function, and the equilibrium that results is called a logit equilibrium. ${ }^{14}$ Decisions are stochastic in a logit equilibrium: all options have a non-zero chance of being selected, with choice probabilities positively related to expected payoffs. In other words, non-optimal choices can occur, but the probability of this is inversely related to their cost. In the context of the present paper, logit equilibrium analysis therefore predicts that contributions are lower when they are more costly, i.e. when the internal return is small. This prediction is borne out by the data. Fig. 1 shows that for a fixed group size and external return, contributions are significantly higher with a high internal return. Behavioral noise alone, however, cannot explain the other treatment effects: the impact of group size and the external return on contribution levels suggest the importance of 'other-regarding' preferences.

When individuals care about raising others' payoffs, perhaps because of altruism or a sense of obligation, we can model preferences as including own and others' earnings. The simplest model of altruism is a linear one, in which a person's utility is modeled as one's own monetary payoff plus the sum of others' monetary payoffs, weighted by an altruism parameter $\alpha$ (e.g. Ledyard, 1995; Anderson et al., 1998). One advantage of the logit equilibrium approach is that noisy decision-making and altruism can be combined into a single model, in which contributions are sensitive to changes in both the internal and external returns and group size. The relative importance of altruism and logit parameters can then be estimated using standard maximum-likelihood techniques. We allow for individual

\footnotetext{
${ }^{14}$ See Anderson et al. (1998) for a theoretical analysis of logit equilibria in public goods games. Offerman et al. (1998) and Goeree and Holt (2000) use this type of equilibrium to analyze step-level public goods games with a binary choice of whether or not to contribute. Palfrey and Prisbrey (1997) use a similar error specification.
} 
differences by estimating a model in which individual-specific altruism parameters are drawn from common distributions.

Simple introspection suggests that altruistic motives, if they are important, may not be linear. For example, a person who is willing to give up 10 cents to produce a dollar for somebody else, may not be willing to give up a hundred dollars, knowing that a thousand dollars will then be given to another randomly selected individual. Or would the person give up a hundred dollars to give one dollar to each of a thousand people? We will also consider a non-linear specification where variations in group size and external returns will help identify non-linearities. A natural way to introduce non-linear altruism is to describe an individual's utility as a non-linear function of own and others' earnings. Specifically, we will use a Cobb-Douglas specification to model altruism, again incorporating some decision error via a logit formulation. ${ }^{15}$

First, let us introduce some notation. The public goods game discussed in this paper has a linear payoff structure. Individual token endowments are denoted by $\omega$ and each token not contributed to the public good is worth $v$ cents. An individual $i$ who contributes $x_{\mathrm{i}}$ tokens to the public good earns $\nu\left(\omega-x_{\mathrm{i}}\right)$ cents for the tokens kept. In addition, each token contributed yields $m_{\mathrm{I}}$ cents for the contributor and $m_{\mathrm{E}}$ cents for each of the other $(n-1)$ group members. Using the terminology presented above, the internal return is $m_{\mathrm{I}}$ and the external return is $m_{\mathrm{E}}$. The expected payoff to player $i$, denoted by $\pi_{\mathrm{i}}^{\mathrm{e}}\left(x_{\mathrm{i}}\right)$, is: $\pi_{\mathrm{i}}^{\mathrm{e}}\left(x_{\mathrm{i}}\right)=\nu\left(\omega-x_{\mathrm{i}}\right)+m_{\mathrm{I}} x_{\mathrm{i}}+$ $m_{\mathrm{E}}(n-1) x_{\mathrm{j}}^{\mathrm{e}}$, where $x_{\mathrm{j}}^{\mathrm{e}}$ is the expected contribution of each of the $(n-1)$ other people in the group. Note that the constant marginal values produce linear payoff functions that are maximized at full free riding when $v>m_{\mathrm{I}}$, as is the case in all of our treatments.

The linear altruism model is obtained by replacing the expected payoff $\pi_{\mathrm{i}}^{\mathrm{e}}\left(x_{\mathrm{i}}\right)$ by a weighted sum: $U_{\mathrm{i}}=\pi_{\mathrm{i}}^{\mathrm{e}}+\alpha(n-1) \pi_{\mathrm{j}}^{\mathrm{e}}$, where the altruism parameter, $\alpha$, is typically assumed to be between 0 and 1 . In the linear altruism model, an individual is willing to give up at most $\$ \alpha$ in order to increase others' earnings by $\$ 1$. With linear altruism and linear payoffs, the resulting utility is linear in $x_{\mathrm{i}}$, so full contribution is optimal if $\alpha$ is large enough to make the coefficient of $x_{\mathrm{i}}$ positive, and full free-riding is optimal if the coefficient of $x_{\mathrm{i}}$ is negative. Of course, the levels of $\alpha, v, m_{\mathrm{E}}, m_{\mathrm{I}}$ and $n$ determine the cost of not choosing the optimal decision of full contribution or full free-riding.

Noisy decision-making is introduced via a standard logit probabilistic choice rule, which implies that the choice probabilities are proportional to an exponential function of the expected payoffs:

\footnotetext{
${ }^{15}$ Andreoni and Miller (2000) report some asymmetric pie-sharing experiments in which a person can give up money that is then multiplied by a constant and given to a randomly selected other participant. They consider Cobb-Douglas and other specifications to explain the observed tendency for individuals to give up money when the conversion rate into others' earnings is high.
} 


$$
P\left(x_{\mathrm{i}}\right)=\frac{\exp \left(U_{\mathrm{i}}\left(x_{\mathrm{i}}\right) / \mu\right)}{\sum_{x=0}^{25} \exp \left(U_{\mathrm{i}}(x) / \mu\right)}
$$

where the denominator ensures that the probabilities add up to 1 . The error parameter, $\mu$, determines the sensitivity of decisions to payoffs. When $\mu$ is very large, payoff differences get washed out, and behavior is close to being random. For a small value of $\mu$, however, the decision with the highest payoff is very likely to be selected, i.e. behavior is close to being rational.

The particular parameterization in Eq. (1), with $U_{\mathrm{i}}$ determined by the linear altruism model, can be used to estimate the effects of altruism and error. The probability that individual $i$ contributes $x_{\mathrm{i}}$ tokens is given by (1) and assuming that decisions are independent, the likelihood function is simply given by a product of these decision probabilities. ${ }^{16}$ Hence, $\ln (L)=\Sigma_{\mathrm{i}} \ln \left(P\left(x_{\mathrm{i}}\right)\right)$ and estimates of $\mu$ and $\alpha$ can be obtained by maximizing the log-likelihood function with respect to these parameters. The top row of Table 2 gives the results for this linear model. It is clear that the Nash prediction of no error (i.e. $\mu=0$ ) can be rejected at very low significance levels. The interpretation of the linear altruism parameter, $\alpha=0.1$, is that a person is willing to give up 10 cents to give $\$ 1$ to another person.

Palfrey and Prisbrey (1997) estimate a significant 'warm-glow' altruism effect

Table 2

Maximum-likelihood estimates (standard errors in parentheses)

\begin{tabular}{lclll}
\hline & Altruism parameter & Error parameter & $\log (L)$ & M.S.D. \\
\hline Homogeneous linear model & $\alpha=0.10(0.01)$ & $\mu=19(3)$ & -1011.3 & 2.98 \\
Homogeneous warm glow model & $g=0.11(0.02)$ & $\mu=26(6)$ & -1020.2 & 5.79 \\
Combined homogeneous model & $\alpha=0.14(0.04)$ & $\mu=22(5)$ & -1010.4 & 2.62 \\
& $g=-0.10(0.10)$ & & & \\
& & & & \\
Heterogeneous linear model & $\alpha=0.12(0.24)^{\mathrm{a}}$ & $\mu=17(3)$ & -847.1 & 3.58 \\
Linear model & $\alpha_{0}=0.10(0.02)$ & $\mu=17(3)$ & -1006.9 & 2.69 \\
Distribution of $\alpha$ values & $\sigma_{\alpha}=0.14(0.04)$ & & & \\
Non-linear Cobb-Douglas model & $\beta=0.13(0.03)$ & $\mu=0.12(0.02)^{\mathrm{b}}-1010.6$ & 2.37 \\
\hline
\end{tabular}

${ }^{a}$ This is the average of the individual altruism parameter estimates (standard deviation of the estimates is in parentheses). Ranked from low to high, the individual altruism parameters were estimated to be: $-0.5,-0.34,-0.25,-0.24,-0.22,-0.21,0.05,0.08,0.1,0.12,0.14,0.14,0.14$, $0.14,0.15,0.16,0.16,0.18,0.2,0.23,0.25,0.26,0.32,0.33,0.36,0.39,0.41,0.43,0.45$, where the three perfect Nash players are have been omitted since their behavior is consistent with a range of altruism parameter levels. Including them at 0 would reduce the average to 0.11 .

${ }^{\mathrm{b}}$ The $\mu$ estimate for the Cobb-Douglas is of a different order of magnitude because the payoffs have been transformed using the natural logarithm.

\footnotetext{
${ }^{16}$ There is, of course, the possibility that the ten choices made by one individual are drawn from a different distribution than the choices made by someone else, which we accommodate below by allowing for heterogeneity among individuals.
} 
in their data, but find no evidence for (linear) altruism. ${ }^{17}$ Since a change in the external return, $m_{\mathrm{E}}$, has no effect on contributions in a model with only warmglow altruism, our data do not seem to support such a model. The rough correlation between group size and contributions is another indication for the presence of altruism rather than pure warm glow. A more convincing test for altruism versus warm glow is obtained by comparing the likelihoods of the two models. The second and third rows in Table 2 give the results for the warm glow model, in which player $i$ 's utility function is given by: $U_{\mathrm{i}}=\pi_{\mathrm{i}}^{\mathrm{e}}+g x_{\mathrm{i}}$, and the combined model in which $U_{\mathrm{i}}=\pi_{\mathrm{i}}^{\mathrm{e}}+\alpha(n-1) \pi_{\mathrm{j}}^{\mathrm{e}}+g x_{\mathrm{i}}$. The warm glow parameter $g$ is the utility obtained from contributing one token (independent of how much it benefits others). The second row shows that warm glow by itself provides a worse fit of the data. The third row shows that inclusion of a warm glow term in the linear altruism model yields error and linear altruism parameters that are not significantly different from the ones in the first row, and the warm-glow parameter in this combined model is insignificant.

Because some people appear to be more altruistic than others, we also consider models that allow for individual differences. ${ }^{18}$ We first estimate a linear altruism model with individual-specific altruism coefficients, $\alpha_{\mathrm{i}}$, and a common error parameter, $\mu$. Fig. 2 shows the individual altruism estimates (with light bars for female subjects and dark bars for male subjects). There is no evidence that women in our sample are more altruistic than men, but the altruism estimates for the men tend to be more extreme. ${ }^{19}$ Estimates range between -0.5 and 0.5 with a mean of $\bar{\alpha}=0.12$ (standard deviation of 0.24 ). Only one negative estimate is significant at the $5 \%$ level; overall, most positive estimates for men and women are significantly

\footnotetext{
${ }^{17}$ Their model involves a binary decision, contribute or not, and randomly varying private values for keeping a token. The warm glow model specifies that the act of contributing provides utility independent of how much it actually benefits others.

${ }^{18}$ This is supported by previous work that calls attention to the diversity of individual contribution behavior. For example, Andreoni and Miller (2000) find that traditional 'selfish' preferences describe about half of the subjects in their token-sharing experiments, while about $1 / 3$ of subjects divided tokens to provide equal payoffs to both players, and another $20 \%$ gave most tokens to the person with the highest redemption value.

${ }^{19}$ For this model only, we have excluded the three subjects (two male and one female) who did not contribute in any of the ten treatments. Andreoni and Vesterlund (1999) look at gender differences in a two-person dictator game in which the value of a 'token' differs between the first-mover and the receiver. They find that women are more likely to give when it is expensive (that is, when the 'price' of giving is greater than one), and men are more likely to give when it is inexpensive. The price of a contribution, defined as the cost of contributing relative to the benefit to the other, is less than one in each of our treatments. Women give less than men in nine of our ten treatments, and the mean altruism estimate for our data is lower for women (0.10) than for men (0.13), but this difference is not significant. Andreoni and Vesterlund also find that men are more likely to give fully or not at all, while women favor more egalitarian outcomes. In view of their results, it is not surprising that we find the variance of individual altruism estimates to be larger for men (0.07 versus 0.037). The higher variability of male altruism estimates is significant at the $1 \%$ level (one-tailed test) based on a Mann-Whitney $U$-test applied to the ranks of the absolute differences between the individual altruism parameters and the median altruism for the group as a whole.
} 


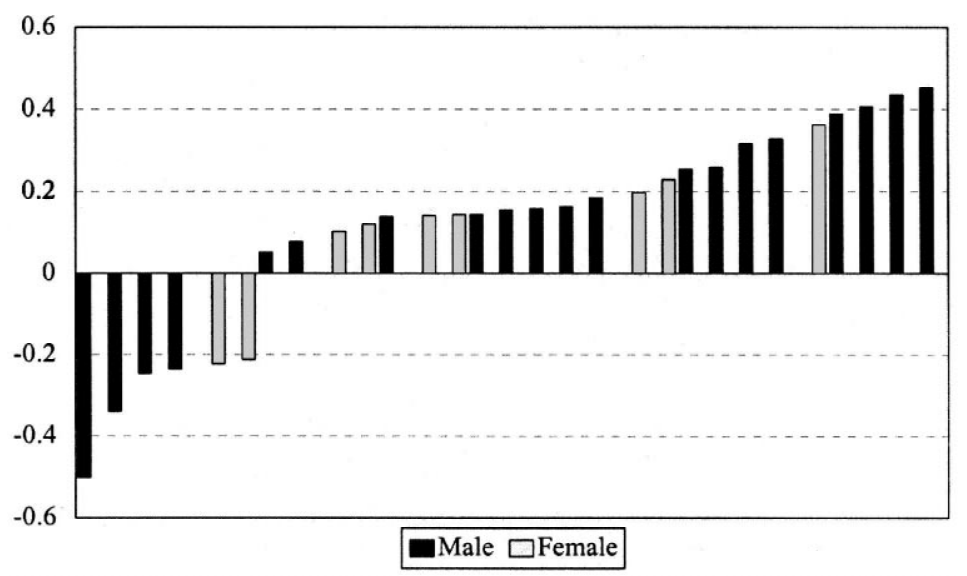

Fig. 2. Individual altruism estimates key: male estimates (dark bars) and female estimates (light bars).

different from zero at the $5 \%$ level. It is not surprising that a model with 28 more parameters results in a better fit of the individual data as indicated by the higher value of the log-likelihood function. However, it does not provide as good a fit of the average contributions by treatment, as can be seen by considering the mean-squared difference, i.e. the sum of squared differences between the actual and predicted number of tokens contributed, divided by the number of treatments. The mean-squared differences are shown in the far-right column of Table 2.

An alternative way to incorporate some heterogeneity is to model the individualspecific altruism coefficients as draws from some population distribution and use the data to estimate the parameters underlying the distribution. For instance, suppose the altruism parameters are drawn from a normal distribution with mean $\alpha_{0}$ and variance $\sigma_{\alpha}^{2}$. Estimation of this model yields a similar value of the error parameter, $\mu=17(3)$, and the mean of the normal population distribution of altruism parameters, $\alpha_{0}=0.10(0.02)$, is quite close to the estimate for the other linear models. However, this model provides a better fit of the data averages than a simple one-parameter linear altruism model, as indicated in the 'M.S.D. column' of Table 2 .

While linear models may be appropriate for some parameter values, they may not apply when 'large' amounts of money are being transferred as is the case for large groups and high external returns. One way to model non-linear tradeoffs between own and others' expected earnings is to specify a non-linear utility function of expected earnings. ${ }^{20}$ Using the Cobb-Douglas specification, player $i$ 's

\footnotetext{
${ }^{20}$ Putting expected earnings in arguments of such a function simply means that the rate at which you are willing to trade off your own expected earnings in order to increase another's expected earnings is non-linear. The function implies that only expected earnings matter, i.e. there is no risk aversion. There is no inconsistency in having non-linear altruism and risk neutrality.
} 
utility function becomes: $U_{\mathrm{i}}\left(x_{\mathrm{i}}\right)=(1-\beta) \ln \left(\pi_{\mathrm{i}}^{\mathrm{e}}\right)+\beta \ln \left((n-1) \pi_{\mathrm{j}}^{\mathrm{e}}\right)$, with $0 \leq \beta \leq$ 1. ${ }^{21}$ The maximum likelihood estimates for the altruism and error parameters are presented in the bottom row of Table 2. The Cobb-Douglas parameter of 0.13 means that, in the absence of any error, a person would divide one dollar by taking 87 cents and giving 13 cents to someone else, which is roughly consistent with the implication of the linear model that a person is willing to give up at most 10 cents to provide an additional dollar to another. In the non-linear altruism model, however, the levels of own and others' payoffs will affect how much a person is willing to give up. For instance, when others are already better off, a person may decide to give less than 13 cents from an extra dollar provided. This non-linear model yields the lowest value of the mean squared deviation in the far right column of Table $2 .^{22}$

Fig. 3 shows the average contribution (thick line) for all ten treatments listed in the same order as in Table 1, together with the predictions of the linear altruism model (thin line without markers) and the non-linear model (thin line with markers). Both models track the data averages remarkably well: except for the decision labeled as number eight (the $n=2, m_{\mathrm{I}}=4$, and $m_{\mathrm{E}}=2$ treatment), all predicted averages are close to the actual ones. While the non-linear model does not result in a significantly higher likelihood, it outperforms the linear model in terms of reproducing the treatment effects.

One way in which the non-linear model improves prediction is in paired cases where the total amount of money being transferred to others is constant, but the money goes to one person in one case and is divided among three others in the other case. For example, consider the first pair of treatments in Table 3. The internal return is 2 cents, but the external return is either 6 cents to one person, or 2 cents to each of three others. The contributions are 7.7 in the first case, but only

\footnotetext{
${ }^{21}$ The logit equilibrium condition is more complicated for the non-linear altruism model. Note that the logit choice probabilities in (1) remain unchanged when a constant is added to expected payoffs. Hence, others' expected contributions have no effect on decisions in the linear altruism model. For the non-linear model, however, the expected contribution of each of the $(n-1)$ other people, $x_{\mathrm{j}}^{\mathrm{e}}$, does affect the choice probabilities. Since the logit probabilities, in turn, determine $x_{\mathrm{j}}^{\mathrm{e}}$, the equilibrium level of contributions has to be calculated as a fixed point. In this way, the log-likelihood function is evaluated at each combination of parameter values $(\mu, \beta)$. An iterative search is then used to determine the values of $\mu$ and $\beta$ that maximize the log-likelihood.

${ }^{22}$ We also estimated a model suggested by Fehr and Schmidt (1999) in which utility is given by your own payoff plus an 'envy' parameter times the difference between the other's payoff and one's own payoff (when this difference is positive) plus a 'guilt' parameter times the difference between one's own payoff and the other's payoff (when this difference is positive). This model of asymmetric inequity aversion assumes that the envy parameter is greater than the guilt parameter, and that both are positive. When applied to our data, however, the envy parameter is estimated to be $-0.22(0.03)$, and the guilt parameter is estimated to be 0.05 (0.03), with the standard errors given in parentheses. In other words, individuals prefer that others earn more money (indicated by the significant negative envy parameter), which may not be surprising given the significant altruism parameter that we estimated. Inequity aversion may be more important in other contexts (e.g. bargaining) where the focus is more clearly on issues of division. See Bolton and Ockenfels (2000) for an alternative way to model inequity aversion.
} 


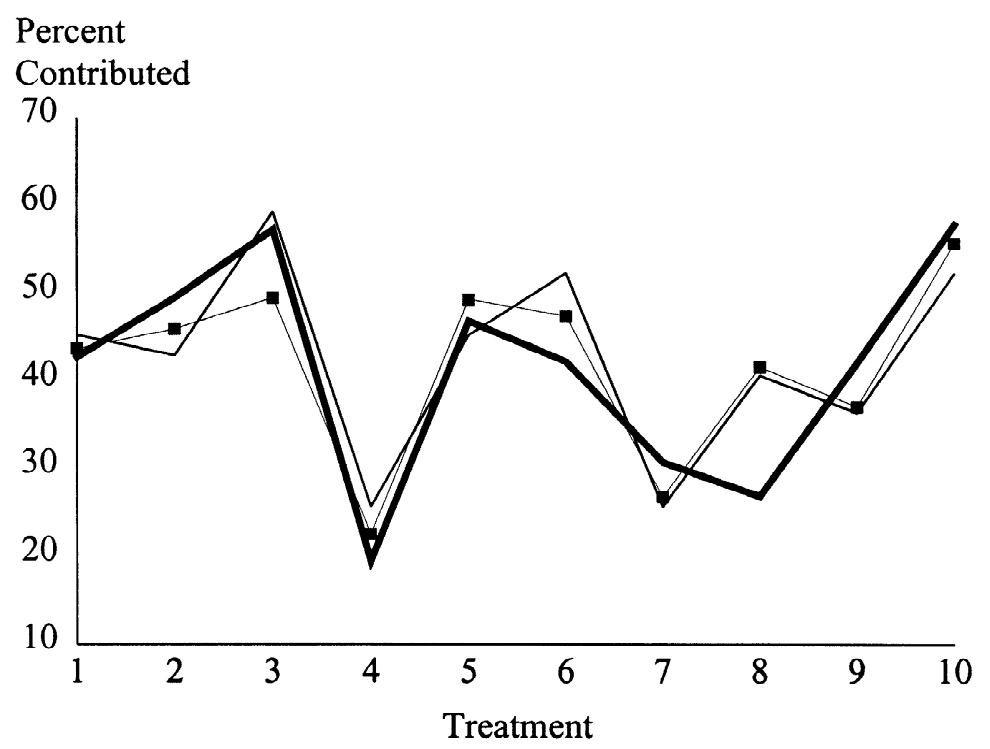

Fig. 3. Average token contributions: data and predictions. Key: Data averages (thick line), linear altruism model (thin line), and Cobb-Douglas model (filled squares).

4.9 in the second, despite the fact that the linear model predicts the same contribution of 6.4 in both cases. A similar pattern is observed in the other two treatments: contributions are higher when an amount of money is given to one person than when the same total is divided among three others. Notice that the Cobb-Douglas model predictions in the last column capture the decline in contributions for each treatment pair, although the predicted differences are generally less than the observed differences.

In order to test the robustness of our predictions, in particular with respect to the Cobb-Douglas model's predictions for larger group sizes, we apply the estimates reported above to a new set of data using groups of size two, four and 12. Fig. 4 gives data together with out-of-sample predictions for the linear and Cobb-

Table 3

Comparison of contributions with constant total return

\begin{tabular}{lccc}
\hline $\begin{array}{l}\text { Treatment } \\
\left(n, m_{\mathrm{I}}, m_{\mathrm{E}}\right)\end{array}$ & $\begin{array}{l}\text { Data } \\
\text { average }\end{array}$ & $\begin{array}{l}\text { Homogenous } \\
\text { linear model }\end{array}$ & $\begin{array}{l}\text { Cobb-Douglas } \\
\text { model }\end{array}$ \\
\hline$(2,2,6)$ & 7.7 & 6.4 & 6.7 \\
$(4,2,2)$ & 4.9 & 6.4 & 5.6 \\
$(2,4,6)$ & 11.7 & 11.3 & 12.3 \\
$(4,4,2)$ & 10.7 & 11.3 & 10.9 \\
$(2,4,12)$ & 14.5 & 13.1 & 14.0 \\
$(4,4,4)$ & 10.6 & 13.1 & 11.9 \\
\hline
\end{tabular}




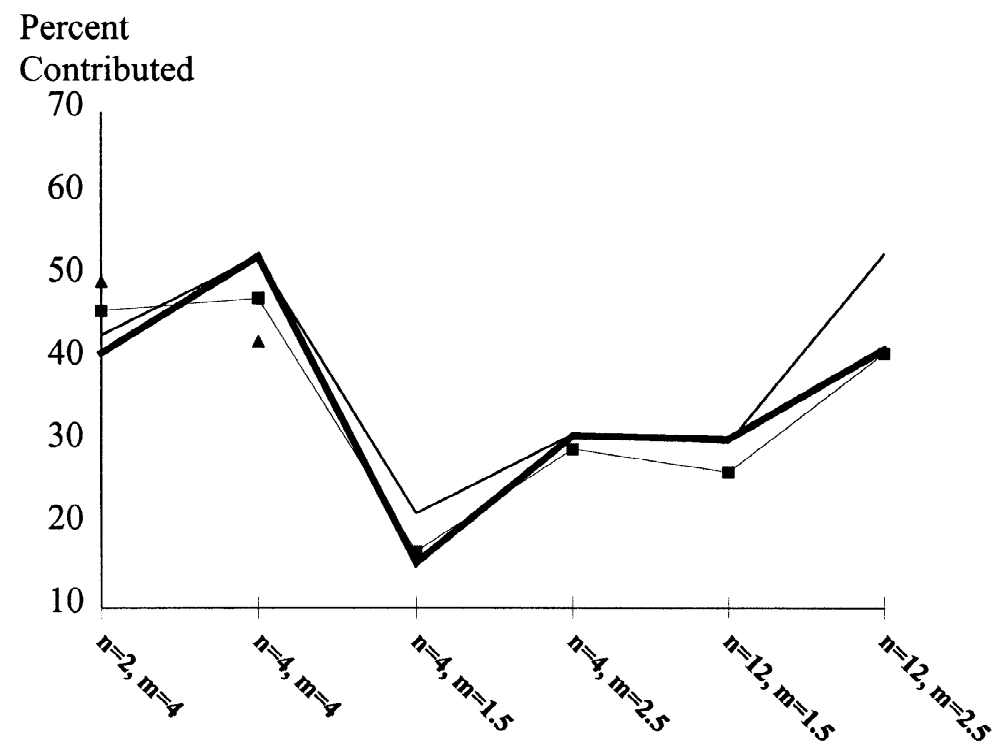

Fig. 4. Average token contributions: data and out-of-sample predictions: Key: Data averages from original treatments two and six (filled triangles), data averages from new experiment (thick line), linear altruism model(plain thin line), and Cobb-Douglas model (filled squares).

Douglas models. These decisions were made by 12 subjects at the University of South Carolina, who were paid for one of eight decisions made without feedback. The treatments provide a direct measure of the effect of changing group size, since the return to the public good is constant between treatments 1 and 2, 3 and 5, and 4 and 6 (the internal and external return were equal in all six of these treatments). For example, the first treatment in Fig. 4 corresponds to treatment 2 in Fig. 3, which uses a group size of two and a return to both individuals of four cents. Similarly, the second treatment in Fig. 4 corresponds to treatment 6 in Fig. 3. For comparison, the data points from the original treatments (reported in Table 2 and Fig. 3) are shown as filled triangles in Fig. 4. No direct comparisons exist for the remaining four treatments, which are given in the labels for the figure. ${ }^{23}$ The

\footnotetext{
${ }^{23}$ The earnings from a token kept was 10 cents in the new experiment (twice as much as in our original treatments 1 through 10). Similarly, the return from a token contributed was twice as much. Therefore, the marginal return to the public good must be scaled by half to be compared with treatments 1-10. For example, when a token contributed earns 3 cents and a token kept earns 10 cents, this is comparable to a situation in which a token contributed earns 1.5 cents and a token kept earns 5 cents. Marginal return is thus labeled as 1.5 in Fig. 4. In addition, two treatments of the new experiments changed only the token endowment (but kept the same group size and marginal return). There was little difference in percentage contributions when endowment was doubled, therefore we averaged treatments with the same group size and marginal return, but different endowment. The data averages for treatments four and six in Fig. 4 are thus averages over two treatments.
} 
Cobb-Douglas model predicts the out-of-sample data averages remarkably well. In particular it captures the effect of an increase in group size from four to 12 holding constant the return to the public good. In contrast, the linear model over-estimates the effect of this increase in group size between treatments four and six in Fig. 4.

\section{Conclusions}

Our experiment measures the relative importance of altruism and behavioral noise in public goods experiments. Palfrey and Prisbrey (1997) and Andreoni (1995) approached this issue with clever changes in the structure of the public goods game, and they find some evidence for both 'kindness' and 'confusion.' Following Carter et al. (1992) we preserve the basic structure of the standard linear public goods game and decompose changes in the marginal value of the public good into independent changes in the internal return, which determines the net cost of giving, and the external return, which determines the benefit to others. In practice, the internal return is affected by factors such as tax deductions that reduce the net cost of giving, whereas contribution matching by employers or other matching gifts tends to increase both internal and external returns. The experiment was implemented as a one-shot game to mitigate the repeated game effects, thereby allowing us to observe individual decisions over a range of treatments.

The data allow us to make inferences about the effects of altruism versus noisy decision-making. The significant effect of a change in external return and group size indicates some altruism, while the effect of a change in internal return is evidence of errors due to randomness or unmodeled factors. Like Carter et al. (1992) we observe that both effects are positive, and that a change in the cost of contributing (given by the internal return) has the largest effect on average contributions. These results are further supported by estimation of a parametric model. Altruism and logit parameters are significant and of reasonable magnitudes both in linear and non-linear altruism specifications. We should stress that our results do not suggest that other factors (reciprocity and strategic motives, for example) are not at play when people choose to contribute. However, the current one-shot design allows us to better disentangle the effect of altruism than is possible with a repeated-matching protocol.

There is considerable heterogeneity among our subjects. When a model is estimated that allows for different altruism parameters for each individual, the average estimate is quite close to the 0.10 estimate for the homogeneous model, indicating that the representative individual would give up at most 10 cents to raise others' earnings by a dollar. The individual altruism estimates, however, range from -0.45 to 0.5 . Most of the estimates are positive; one negative coefficient is barely significant at the five percent level, while all other negative coefficients are 
not significant. On average the altruism parameters are about the same for men and women, although the male altruism estimates are significantly more dispersed.

These results also give us some perspective on the nature of altruism. The sensitivity of contributions to internal return and group size are evidence that altruism is not simply of the warm-glow variety, i.e. giving for the sake of giving. In addition, a non-linear model fits the treatment averages better than the linear altruism model. It explains the smaller effect of extreme increases in external return and group size. The non-linear model also correctly predicts higher contributions when the return from a contribution is given to one person rather than divided equally among three others. This is consistent with the notion that altruism probably evolved in family or small-group interactions, and implies that charities should take advantage of whatever opportunities they have to target contributions to particular individuals or small groups.

\section{Acknowledgements}

This work was funded in part by the National Science Foundation (SBR9753125 and SBR-9818683). The research assistance provided by Cara Carter and Todd Farnworth is gratefully acknowledged.

\section{Appendix A. Instructions}

This is an experiment about decision making. You will be paid for participating, and the amount of money you earn depends on the decisions that you and the other participants make. At the end of today's session you will be paid privately and in cash for your decisions. Several research foundations have provided the funds for this experiment.

You will never be asked to reveal your identity to anyone during the course of the experiment. Your name will never be associated with any of your decisions. In order to keep your decisions private, please do not reveal your choices to any other participant.

At this time, you will be given $\$ 6$ for coming on time. All the money that you earn after this will be yours to keep, and your earnings will be paid to you in cash at the end of today's experiment.

\section{This experiment}

In this experiment you will be asked to make a series of choices about how to allocate a set of tokens. You and the other subjects will be randomly assigned to groups, and you will not be told each others' identities.

In every choice you will be told how many people are in your group. In each choice you will have 25 tokens to allocate. You must choose how many of these 
tokens you wish to keep and how many tokens you wish to invest. The amount of money that you earn depends on how many tokens you keep, how many tokens you invest, and how many tokens the others in your group invest.

\section{Examples of choices you will make in this experiment}

Each choice that you make is similar to the following:

Example 1: You are in a group of size 2 (you plus one other). Both of you have 25 tokens to allocate. You will earn 5 cents for each token you keep. For each token you invest, you will earn 4 cents and the other person will earn 3 cents (a total of 7 cents for both of you together).

For each token the other person keeps, this person will earn 5 cents. For each token the other person invests, this person will earn 4 cents and you will earn 3 cents (a total of 7 cents for the group).

To summarize, you will earn:

5 cents times the number of tokens you keep

+4 cents times the number of tokens you invest

+3 cents times the number of tokens the other person in your group invests

Keep __ tokens Invest _ tokens (These choices must sum to 25 tokens)

You can choose any number of tokens to keep and any number to invest, but the number of tokens you keep plus the number of tokens you invest must sum to the total number of tokens you have been given to allocate.

Please feel free to use your own calculator, or one provided by the experimenter, to verify earnings and to ensure that all tokens have been allocated.

To be sure you understand how your earnings would be calculated in this example, please fill out the following. Choose numbers for tokens that you keep, the tokens that you invest, and the tokens that the other person invests. This is only to illustrate how your earnings are calculated. In the actual experiment, everyone will make their own choice and we will calculate all earnings for you.

If I keep _ tokens and invest _ tokens; and the other person in my group invests _ tokens, I will earn:

_- cents for the tokens that I keep (5 cents each)

_ cents for the tokens that I invest (4 cents each)

- cents for the tokens the other person invests ( 3 cents each)

For a total of: _- cents.

Please fill this out, and we will come to each of you individually to answer any questions that you have and to check your answers.

When you are done, you may proceed to the second example: 
Example 2: You are in a group of size 4 (you plus 3 others). Each of you has 25 tokens to allocate. You will earn 5 cents for each token you keep. For each token you invest, you will earn 2 cents and each of the other three people in your group will earn 3 cents (a total of 11 cents for all four of you together).

For each token another person in your group keeps, this person will earn 5 cents. For each token this person invests, this person will earn 2 cents, and each of the other people in your group will earn 3 cents (a total of 11 cents for the group).

To summarize, you will earn:

5 cents times the number of tokens you keep

+2 cents times the number of tokens you invest

+3 cents times the number of tokens the other people in your group invest

Keep __ tokens Invest _ tokens (These choices must sum to 25 tokens)

Again, to be sure you understand how your earnings would be calculated in this example, please fill out the following:

If I keep __ tokens and invest __ tokens; and the other three people in my group invest a total of _ tokens, I will earn:

_ cents for the tokens that I keep ( 5 cents each)

_ cents for the tokens that I invest (2 cents each)

_ cents for the tokens the other three people invest ( 3 cents each)

For a total of: _ cents.

\section{Earning money in this experiment}

You will be asked to make ten allocation decisions like the examples we have just discussed. We will calculate your earnings as follows:

After all your decision sheets have been collected, we will verify that everyone has completed all decisions and that all 25 tokens have been allocated for each choice. Then we will roll a ten-sided die. The number that appears on the die will determine which one of your decisions we will carry out. For example, if we roll a 1 you will be paid for your first decision. If we roll a 0 you will be paid for your 10th decision (the die contains the numbers 0 through 9). You will be paid only for the decisions that you and the others in your group make for this one decision. For example, if a 1 is rolled you will be paid based on the decisions you and the others in your group made in decision 1. You will not be paid for any other decisions.

After determining which decision is chosen, we will randomly assign you to groups of the size specified in this decision. We will do this by drawing numbered ping-pong balls. For example, if a decision is chosen in which you are in a group of size four, we will draw four ping-pong balls. The subjects whose ID numbers correspond to these four draws will be in one group. We would then draw another four balls to determine which subjects are in the second group. This would be repeated until all subjects are assigned to a group. 
You will then earn money based on the number of tokens you kept in this decision, the number of tokens you invested in this decision, and the number of tokens invested by the other(s) in your group (the total number invested by each other person in your group) in this decision.

After all choices are made, we will conduct another decision-making experiment. We will compute your earnings for this part during the second experiment. At the end of the second experiment, we will return an earnings report to you so that you may see how much money you earned in this portion of the experiment. You will only be told the total number of tokens invested by the other(s) in your group. You will not be told who you are matched with.

During the experiment, you are not permitted to speak or communicate with the other participants. If you have a question while the experiment is going on, please raise your hand and one of us will come to your desk to answer it. At this time, do you have any questions about the instructions or procedures? If you have a question, please raise your hand and one of us will come to your seat to answer it.

On the following pages are the ten choices we would like you to make. Please fill out the form, taking the time you need to be accurate. When everyone is done we will collect the forms.

\section{Decision sheet}

Please fill in all of the blanks for each choice below. Make sure that the number of tokens listed under Keep plus the number listed under Invest equals 25 tokens.

Choice 1. You are in a group of size 4 (you plus three others). Each of you have 25 tokens to allocate. You will earn 5 cents for each token you keep. For each token you invest, you will earn 4 cents and each of the other three people in your group will earn 2 cents (a total of 10 cents for all four of you together).

For each token another person in your group keeps, this person will earn 5 cents. For each token this person invests, this person will earn 4 cents, and each of the other people in your group will earn 2 cents (a total of 10 cents for the group).

To summarize, you will earn:

5 cents times the number of tokens you keep

+4 cents times the number of tokens you invest

+2 cents times the number of tokens the other people in your group invest

Keep __ tokens Invest _ tokens. (These choices must sum to 25 tokens) (The other nine choices were presented in a similar manner.) 


\section{Appendix B. Individual data}

\begin{tabular}{|c|c|c|c|c|c|c|c|c|c|c|}
\hline \multirow{4}{*}{$\begin{array}{l}\text { Group size }(n) \\
\text { Internal return }(\$) \\
\text { External return }(\$)\end{array}$} & \multicolumn{10}{|c|}{ Treatment } \\
\hline & & & 2 & 2 & 2 & 4 & 4 & 4 & 4 & \\
\hline & 0.02 & 0.04 & 0.04 & 0.04 & 0.04 & 0.02 & 0.02 & 0.04 & 0.04 & 0.04 \\
\hline & 0.06 & 0.02 & 0.04 & 0.06 & 0.12 & 0.02 & 0.06 & 0.02 & 0.04 & 0.06 \\
\hline \multicolumn{11}{|c|}{ Individual token contribution decisions: University of Virginia subjects } \\
\hline Subject 1 & 10 & 5 & 15 & 15 & 15 & 10 & 25 & 20 & 20 & 25 \\
\hline Subject 2 & 1 & 7 & 7 & 1 & 0 & 2 & 2 & 6 & 0 & 3 \\
\hline Subject 2 & 15 & 17 & 20 & 20 & 25 & 0 & 10 & 15 & 5 & 25 \\
\hline Subject 4 & 0 & 3 & 10 & 15 & 23 & 0 & 5 & 15 & 20 & 25 \\
\hline Subject 5 & 15 & 0 & 20 & 12 & 23 & 3 & 20 & 17 & 9 & 20 \\
\hline Subject 6 & 0 & 3 & 5 & 5 & 5 & 0 & 0 & 3 & 3 & 5 \\
\hline Subject 7 & 0 & 25 & 25 & 25 & 25 & 5 & 20 & 25 & 15 & 25 \\
\hline Subject 8 & 5 & 5 & 15 & 15 & 15 & 5 & 5 & 10 & 10 & 15 \\
\hline Subject 9 & 0 & 0 & 0 & 0 & 0 & 0 & 0 & 0 & 0 & 0 \\
\hline Subject 10 & 0 & 0 & 0 & 0 & 0 & 0 & 0 & 0 & 0 & 0 \\
\hline Subject 11 & 7 & 0 & 10 & 5 & 18 & 2 & 15 & 7 & 12 & 20 \\
\hline Subject 12 & 7 & 12 & 17 & 20 & 24 & 1 & 14 & 20 & 15 & 21 \\
\hline Subject 13 & 20 & 14 & 20 & 20 & 20 & 14 & 18 & 20 & 20 & 22 \\
\hline Subject 14 & 0 & 0 & 0 & 0 & 0 & 0 & 0 & 0 & 0 & 0 \\
\hline Subject 15 & 7 & 15 & 15 & 18 & 19 & 1 & 7 & 17 & 13 & 20 \\
\hline Subject 16 & 10 & 5 & 15 & 18 & 20 & 8 & 12 & 12 & 15 & 18 \\
\hline \multicolumn{11}{|c|}{ Individual token contribution decisions: University of South Carolina subjects } \\
\hline Subject 17 & 14 & 10 & 12 & 12 & 15 & 11 & 14 & 10 & 13 & 14 \\
\hline Subject 18 & 2 & 5 & 6 & 4 & 2 & 7 & 1 & 3 & 5 & 5 \\
\hline Subject 19 & 4 & 1 & 5 & 2 & 1 & 3 & 10 & 1 & 5 & 1 \\
\hline Subject 20 & 19 & 7 & 5 & 8 & 20 & 6 & 16 & 9 & 6 & 15 \\
\hline Subject 21 & 15 & 14 & 20 & 15 & 10 & 7 & 6 & 8 & 3 & 21 \\
\hline Subject 22 & 3 & 9 & 25 & 6 & 4 & 7 & 8 & 10 & 25 & 5 \\
\hline Subject 23 & 15 & 10 & 15 & 15 & 15 & 15 & 20 & 20 & 20 & 20 \\
\hline Subject 24 & 20 & 1 & 10 & 20 & 23 & 5 & 24 & 12 & 10 & 25 \\
\hline Subject 25 & 10 & 11 & 20 & 13 & 22 & 8 & 12 & 8 & 12 & 10 \\
\hline Subject 26 & 11 & 5 & 17 & 25 & 23 & 12 & 18 & 20 & 21 & 20 \\
\hline Subject 27 & 4 & 0 & 15 & 15 & 25 & 5 & 25 & 10 & 18 & 20 \\
\hline Subject 28 & 0 & 10 & 10 & 0 & 5 & 0 & 0 & 10 & 5 & 5 \\
\hline Subject 29 & 2 & 1 & 4 & 5 & 7 & 1 & 3 & 2 & 3 & 5 \\
\hline Subject 30 & 11 & 11 & 9 & 8 & 14 & 7 & 12 & 12 & 10 & 16 \\
\hline Subject 31 & 10 & 1 & 13 & 23 & 25 & 2 & 5 & 5 & 13 & 20 \\
\hline Subject 32 & 9 & 8 & 16 & 15 & 20 & 9 & 10 & 15 & 12 & 12 \\
\hline
\end{tabular}

\section{References}

Anderson, S.P., Goeree, J.K., Holt, C.A., 1998. A theoretical analysis of altruism and decision error in public goods games. Journal of Public Economics 70 (2), 297-323.

Andreoni, J., 1995. Cooperation in public goods: kindness or confusion? American Economic Review 85, 891-904. 
Andreoni, J., Miller, J.H., 2000. Giving According to GARP: An Experimental Study of the Rationality of Altruism. University of Wisconsin, Working paper.

Andreoni, J., Vesterlund, L., 1999. Which is the fair sex? Gender differences in altruism, Quarterly Journal of Economics, forthcoming.

Bolton, G.E., Ockenfels, A., 2000. A theory of equity, reciprocity, and competition. American Economic Review 90 (1), 166-193.

Brandts, J., Schram, A., 1995. Tacit Cooperation or Noise in Voluntary Contribution Mechanism Experiments: Applying the Contribution Function. CREED working paper.

Carter, J.R., Drainville, B.J., Poulin, R.P., 1992. A Test for Rational Altruism in a Public-Goods Experiment. College of Holy Cross, Working paper.

Chewning, E.G., Coller, M., Laury, S.K., 2000. Voluntary contributions to a multiple threshold public good. In: Isaac, R.M. (Ed.), Research in Experimental Economics (in press)

Fehr, E., Schmidt, K.M., 1999. A theory of fairness, competition and cooperation. Quarterly Journal of Economics 114 (3), 769-816.

Goeree, J.K., Holt, C.A., 2000. An Explanation of Anomalous Behavior in Binary-Choice Games: Entry, Voting, Public Goods, and the Volunteers' Dilemma. University of Virginia, Working paper.

Holt, C.A., Laury, S.K., 2000. Theoretical explanations of treatment effects in voluntary contributions games. In: Plott, C., Smith, V. (Eds.), Handbook of Experimental Economic Results. Elsevier, New York, Forthcoming.

Laury, S.K., Walker, J.M., Williams, A.W., 1995. Anonymity and the voluntary provision of public goods. Journal of Economic Behavior and Organization 27, 365-380.

Ledyard, J., 1995. Public goods: a survey of experimental research. In: Kagel, J., Roth, A.E. (Eds.), The Handbook of Experimental Economics. Princeton University Press.

McKelvey, R.D., Palfrey, T.R., 1995. Quantal response equilibria for normal form games. Games and Economic Behavior 10, 6-38.

Offerman, T., Schram, A., Sonnemans, J., 1998. Quantal response models in step-level public goods games. European Journal of Political Economy 14, 89-100.

Palfrey, T.R., Prisbrey, J.E., 1997. Anomalous behavior in linear public goods experiments: how much and why? American Economic Review 87, 829-846.

Siegel, S., 1956. Nonparametric Statistics for the Behavioral Sciences. McGraw-Hill, New York. 